\title{
Isolation of various Arcobacter species from domestic geese (Anser anser)
}

\author{
H. Ibrahim Atabay ${ }^{\mathrm{a}, *}$, Ahmet Unver $^{\mathrm{b}}$, Mitat Sahin ${ }^{\mathrm{b}}$, \\ Salih Otlu ${ }^{\mathrm{b}}$, Mehmet Elmali ${ }^{\mathrm{c}}$, Hilmi Yaman ${ }^{\mathrm{d}}$ \\ ${ }^{a}$ Department of Food Engineering, Faculty of Engineering, İzmir Institute of Technology, \\ Urla, 35430 İzmir, Turkey \\ ${ }^{\mathrm{b}}$ Department of Microbiology, Veterinary Faculty, Kafkas University, Kars, Turkey \\ ${ }^{\mathrm{c}}$ Department of Food Hygiene and Technology, Veterinary Faculty, Kafkas University, Kars, Turkey \\ ${ }^{\mathrm{d}}$ Department of Food Hygiene and Technology, Veterinary Faculty, Afyon Kocatepe University, Afyon, Turkey \\ Received 5 October 2007; received in revised form 5 October 2007; accepted 12 October 2007
}

\begin{abstract}
In this study, the prevalence and distribution of various Arcobacter spp. were investigated in samples taken from the cloacae of healthy domestic geese raised in Turkey. A membrane filtration technique with a non-selective blood agar was employed after enrichment in Arcobacter enrichment broth (AEB) to isolate a wide range of Arcobacter spp. In addition, the isolates were characterized phenotypically and identified at species level using a multiplex-PCR assay. A total of 90 cloacal swab samples taken from geese, collected on three farms (18, 25, 47 samples, respectively), were examined. Of the samples examined, 16 (18\%) were found positive for Arcobacter. One Arcobacter species was isolated from each bird. Of the 16 Arcobacter isolates, 7 (44\%), 7 (44\%) and 2 (12.5\%) were identified by m-PCR as A. cryaerophilus, A. skirrowii and A. butzleri, respectively. The present study indicates that domestic geese can harbour a variety of Arcobacter spp. in their cloacae. The presence of Arcobacter in geese may be of significance as reservoirs in their dissemination. Detailed research is needed for better understanding of the epidemiology and zoonotic potential of this emerging pathogen.
\end{abstract}

(C) 2007 Elsevier B.V. All rights reserved.

Keywords: Arcobacter; Geese; Poultry; Multiplex-PCR; Prevalence

\section{Introduction}

The genus Arcobacter that presently includes six

* Corresponding author. Tel.: +90 232750 6282; fax: +90 2327506196 .

E-mail address: halilatabay@iyte.edu.tr (H.I. Atabay). species: Arcobacter butzleri, A. cryaerophilus, A. skirrowii, A nitrofigilis, A. cibarius and A. halophilus was first proposed by Vandamme et al. (1991, 1992). 
Furthermore, an autotrophic, obligate microaerophile sulfide-oxidizing Arcobacter (Candidatus Arcobacter sulfidicus) has been described from coastal seawater (Wirsen et al., 2002). Another possible species, detected in aborted pig fetuses and ducks, awaiting for formal description has also been reported by On et al. (2003).

Arcobacter spp. were first isolated from aborted fetuses of livestock (Ellis et al., 1977). The organisms have also been associated with a range of other animal diseases such as reproductive disorders, mastitis and gastric ulcers (Logan et al., 1982; Suarez et al., 1997; de Oliveira et al., 1997). Clinically healthy farm animals were also found to harbour Arcobacter (Van Driessche et al., 2005; Aydin et al., 2007). Arcobacter spp. have also been associated with diarrhoea and occasionally septicemia in humans (Lastovica and Skirrow, 2000; Woo et al., 2001). A. butzleri is the species most often isolated from humans, but $A$. cryaerophilus and more recently A. skirrowii have also been associated with human diseases (Wybo et al., 2004; Prouzet-Mauleon et al., 2006).

Arcobacter spp. have been isolated from a variety of foods comprising poultry, pork and beef (Collins et al., 1996; de Boer et al., 1996; Atabay et al., 2006; Aydin et al., 2007) and water (Rice et al., 1999). Although arcobacters are commonly detected on poultry carcasses, different isolation rates were reported from live birds (Wesley and Baetz, 1999; Kabeya et al., 2003; Atabay et al., 2006). In some studies, no Arcobacter isolation was achieved from the intestines of chickens (Gude et al., 2005) but from 4 to $15 \%$ prevalance rate were reported from different studies conducted in the US (Wesley and Baetz, 1999), Japan (Kabeya et al., 2003) and Denmark (Atabay et al., 2006). Atabay et al. (2006) determined that of the chickens, turkeys and ducks examined in their study, ducks had the highest prevalence of the three poultry species examined. Thus, live birds are considered to have a significant role for the dissemination of Arcobacter spp. A recent study carried out by Dogan and Atabay (2006) demonstrated that domestic geese also harbour Arcobacter spp. However, in the latter study the Arcobacter spp. could not be identified to the species level. So far four Arcobacter spp., A. butzleri, A. cryaerophilus, A. skirrowii and A. cibarius, have been isolated from chickens, ducks and turkeys (Kabeya et al., 2003; Atabay et al., 2006; Houf et al., 2005).
The current study was undertaken to determine the carriage rate and distribution of various Arcobacter spp. in domestic geese raised in Turkey.

\section{Materials and methods}

\subsection{Samples from geese}

A total of 90 cloacal swab samples taken individually from free range clinically healthy domestic geese (Anser anser), collected on three different farms $(18,25,47$ samples, respectively) in Kars, Turkey, were examined.

\subsection{Isolation of Arcobacter by use of membrane filtration technique}

This technique was previously used to isolate arcobacters from various sources. It depends on the ability of arcobacters, but not competitors, to pass through a membrane filter. Five or six drops (ca 100$120 \mu \mathrm{l})$ from enriched samples were inoculated onto a $47 \mathrm{~mm}$ diameter $0.45 \mu \mathrm{m}$ pore size nitrocellulose membrane filter (HAWG047S1, Millipore, Billerica, MA, USA) placed on the surface of a non-selective blood agar plate as described earlier (Atabay and Corry, 1997).

\subsection{Isolation media and method of examination}

Arcobacter enrichment broth (AEB) was prepared in $10 \mathrm{ml}$ quantities using arcobacter enrichment basal medium (Oxoid CM965) incorporating cefoperazone, amphotericin, teicoplanin (CAT) selective supplement (Oxoid SR174E) as described previously (Atabay and Corry, 1998). Blood agar comprised 5\% (v/v) defibrinated sheep blood in blood agar base No. 2 (Oxoid CM271).

Sterile cotton-tipped swabs were employed to take samples from the cloacae of domestic geese (Anser anser). Each swab was moistened with AEB before the sample was taken from the cloaca and put into AEB $(10 \mathrm{ml})$ immediately after the sample collection. The samples were transported to the laboratory. Each inoculated enrichment medium was agitated using a vortex mixer for approximately $1 \mathrm{~min}$ to release bacteria attached to swabs, and incubated microaer- 
obically, which was achieved by using gas generating kits (Oxoid CN35, Hampshire, UK), with loose top at $30{ }^{\circ} \mathrm{C}$ for $48 \mathrm{~h}$. After that, the enriched sample was plated onto a non-selective blood agar plate using the membrane filtration technique mentioned above. Incubation of the plates was also carried out microaerobically at $30{ }^{\circ} \mathrm{C}$ for up to 7 days. The plates were examined daily for any visible growth.

\subsection{Phenotypic characterization of Arcobacter isolates}

One suspect colony from each morphologically different type on each plate was checked by Gram stain and oxidase test. Two or three colonies per plate giving reactions typical for Arcobacter were purified by streaking on blood agar. Phenotypic characterization of the isolates was accomplished using the tests listed in Table 1. All tests were carried out according to previously recommended procedures (On et al., 1996; Atabay et al., 2006) and a reference strain of $A$. butzleri (DCC25) kindly provided by M. Waino and M. Madsen from Danish Institute for Food and Veterinary Research, Denmark, was included as positive control throughout the study.

\subsection{Identification of the Arcobacter isolates using multiplex-PCR}

In order to perform simultaneous identification of A. butzleri, A. cryaerophilus and A. skirrowii, a mutiplex-PCR (m-PCR) assay was employed as described previously (Houf et al., 2000). Briefly, all isolates were grown on blood agar plates micoaerobically at $30{ }^{\circ} \mathrm{C}$ for $48 \mathrm{~h}$ and then, single colony from each isolate was used to extract bacterial DNA. The amplification was performed as described by Houf et al. (2000) and thermal cycles were performed in MJ Mini Cycler (BioRad, Hercules, CA, USA). Amplified products were size-separated by electrophoresis in $1.5 \%$ agarose. Gels were stained with ethidium bromide and a UV light used for visualization.

\section{Results}

\subsection{Phenotypic characterization of Arcobacter isolates}

A total of 16 strains of Arcobacter were isolated from the cloacae of 90 domestic geese in the present

Table 1

Phenotypic characteristics of Arcobacter species isolated from the cloacae of domestic geese raised in Turkey

\begin{tabular}{|c|c|c|c|}
\hline \multirow[t]{2}{*}{ Phenotypic tests used ${ }^{\mathrm{a}}$} & \multicolumn{3}{|l|}{ No. of isolates positive } \\
\hline & Arcobacter cryaerophilus (7) & A. skirrowii (7) & A. butzleri (2) \\
\hline Gram negative & 7 & 7 & 2 \\
\hline Oxidase & 7 & 7 & 2 \\
\hline Catalase & $7^{\mathrm{b}}$ & 7 & $2^{c}$ \\
\hline Urease & 0 & 0 & 0 \\
\hline Alpha-haemolysis & 0 & 0 & 0 \\
\hline \multicolumn{4}{|l|}{ Growth at } \\
\hline Room temperature $\left(\mathrm{O}_{2}\right)$ & 7 & $7^{\mathrm{d}}$ & 2 \\
\hline $30^{\circ} \mathrm{C}\left(\mathrm{O}_{2}\right)$ & 7 & 7 & 2 \\
\hline $30{ }^{\circ} \mathrm{C}\left(\mathrm{mO}_{2}\right)$ & 7 & 7 & 2 \\
\hline $30^{\circ} \mathrm{C}\left(\mathrm{AnO}_{2}\right)$ & 0 & 0 & 0 \\
\hline $37^{\circ} \mathrm{C}\left(\mathrm{mO}_{2}\right)$ & 0 & 2 & 2 \\
\hline $42{ }^{\circ} \mathrm{C}\left(\mathrm{mO}_{2}\right)$ & 0 & 0 & 0 \\
\hline \multicolumn{4}{|l|}{ Growth on media containing } \\
\hline $2.0 \% \mathrm{NaCl}$ & 5 & 7 & 2 \\
\hline $4.0 \% \mathrm{NaCl}$ & 4 & 7 & 0 \\
\hline
\end{tabular}

$\mathrm{O}_{2}$ : aerobically; $\mathrm{mO}_{2}$ : microaerobically; $\mathrm{AnO}_{2}$ : anaerobically; $\mathrm{NaCl}$ : sodium chloride.

${ }^{a}$ All test plates were incubated microaerobically at $30{ }^{\circ} \mathrm{C}$ and were not otherwise stated.

b Two isolates were weakly positive.

c One isolate was weakly positive.

${ }^{\mathrm{d}}$ One isolate grew weakly after 7 days of incubation. 
Table 2

The carriage rates and species distribution of Arcobacter in the cloacae of free range domestic geese in Turkey

\begin{tabular}{lllll}
\hline Origin of samples examined $^{\mathrm{a}}$ & \multicolumn{2}{l}{ No. of samples positive } & & \\
\cline { 2 - 5 } & Arcobacter cryaerophilus & A. skirrowii & A. butzleri & Total number (\%) \\
\hline Kafkas University College & 4 & 1 & 1 & $6(33)^{\mathrm{c}}$ \\
$\quad$ Farm, Kars (18) & & & 1 & $4(16)$ \\
2nd Farm, Kars (25) & 3 & 0 & 6 & $6(13)$ \\
3rd Farm, Kars (47) & 0 & 6 & 2 & $16(18)$ \\
In total (90) & 7 & 7 & 2 & \\
\hline
\end{tabular}

\footnotetext{
${ }^{\text {a }}$ The samples were obtained from different geographical locations in Kars province.

b Number of samples examined.

c The numbers in brackets represent percentages.
}

study. Only one Arcobacter species was isolated from each goose cloacal sample examined. Arcobacter spp. were differentiated from Campylobacter and related organisms by their ability to grow aerobically. All Arcobacter isolates were Gram negative and showed slightly curved rod and/or spiral shape under the microscope. All isolates were oxidase positive. Except for two strains of $A$. cryaerophilus and one of $A$. butzleri that showed weak catalase activity (production of bubbles after $10 \mathrm{~s}$ ), all were strongly catalase positive (instant production of bubbles). All isolates, except for one strain of $A$. skirrowii that showed only traces of growth after 7 days of incubation, were able to grow aerobically at room temperature. In addition, all grew at $30{ }^{\circ} \mathrm{C}$ both aerobically and microaerobically, whereas none of the strains tested was able to grow anaerobically at $30{ }^{\circ} \mathrm{C}$ or microaerobically at $42{ }^{\circ} \mathrm{C}$. Two strains of $A$. butzleri grew microaerobically at $37^{\circ} \mathrm{C}$ but none of the A. cryaerophilus strains and only two of the seven $A$. skirrowii strains were able to grow at $37^{\circ} \mathrm{C}$ under microaerobic conditions. Alpha-haemolysis and urease production were not observed for any strains. Apart from two strains of $A$. cryaerophilus, all Arcobacter strains were able to grow on media containing $2 \% \mathrm{NaCl}$, whereas three $A$. cryaerophilus and two A. butzleri strains did not grow in $4 \% \mathrm{NaCl}$.

\subsection{Differentiation of Arcobacter isolates at species level by m-PCR}

All Arcobacter strains isolated from domestic geese in the present study were identifed to the species level using m-PCR. A 257-bp, 401-bp and 641-bp fragment was observed for A. cryaerophilus, A. butzleri and A. skirrowii, respectively (Houf et al., 2000).

\subsection{The prevalence and distribution of Arcobacter spp. in domestic geese}

Of the 90 samples examined, $16(18 \%)$ were found positive for Arcobacter. Of these strains, 7 (44\%), 7 (44\%) and $2(12.5 \%)$ were identified as A. cryaerophilus, A. skirrowii and A. butzleri, respectively. As summarized in Table 2, of the 18 samples collected from the Kafkas University College Farm, six [33\%; speciated as A. cryaerophilus (4), A. skirrowii (1) and A. butzleri (1)] were positive for Arcobacter. Of the 25 samples from the 2nd farm, 4 (16\%) were positive for Arcobacter of which 3 were identified as $A$. cryaerophilus and 1 as A. butzleri. Of the 47 samples from the 3 rd farm, 6 (13\%) were positive for Arcobacter, all of which were identified as $A$. skirrowii.

\section{Discussion}

The prevalence of Arcobacter spp. was determined as $18 \%$ out of the 90 cloacal swab samples obtained from three different goose flocks in the current study. Since other parts of the goose intestine were not examined, we cannot comment on whether Arcobacter spp. exist in other sites of the intestine. Although only three goose flocks were analysed, a relatively high prevalence of Arcobacter was found in the present study in all three flocks. In a previous study in our laboratory, the prevalence of Arcobacter spp. were found to be $26 \%$ in goose cloacal swab samples 
obtained from the same geographical region (Dogan and Atabay, 2006). In that study, a total of 100 goose samples obtained from four different flocks were examined and the isolates were identified to the genus level. The difference between the two studies may be due to a number of factors such as different sampling time(s) and inclusion of different flocks. It is considered that poultry species may be significant reservoirs of various Arcobacter spp. (Wesley and Baetz, 1999; Houf et al., 2005; Kabeya et al., 2003; Atabay et al., 2006; Gonzales et al., 2007). Birds, including ducks, turkeys and chickens were reported to harbour various Arcobacter spp. in their intestines (Ridsdale et al., 1998; Wesley and Baetz, 1999; Atabay et al., 2006). Isolation of Arcobacter spp. from the cloacae of clinically healthy domestic geese in the present and the previous study (Dogan and Atabay, 2006) suggest that the geese may also be natural carriers of these bacteria. In an earlier study from Denmark (Atabay et al., 2006) ducks were reported to have the highest carriage of Arcobacter spp. with a $75 \%$ prevalence rate at the flock level, while turkeys were found as the second with an $11 \%$ carriage rate and only $4.3 \%$ of the 70 chicken flocks examined were positive for Arcobacter. Ridsdale et al. (1998) also reported that one out of four duck flocks was positive for Arcobacter spp. A carriage rate of approximately $15 \%$ was reported from chicken cloacal swab samples in two independent studies (Wesley and Baetz, 1999; Kabeya et al., 2003). It appears from the gimdings of the current study that the prevalence of Arcobacter spp. in domestic geese may be lower than that of ducks and higher than those of turkeys and chickens.

The carriage rate of Arcobacter was found to vary depending on the goose flocks examined $(33,16$ and $13 \%$ among three different flocks). This may be due to a number of factors such as breeding conditions and/or easy access to contaminated sources like water and/or other animals harbouring Arcobacter. Geese in the region where the samples were obtained are kept on small-scale family farms which also contain several other domestic animals wandering free range. Hence, they may get colonized from the surrounding environment and disseminate the organisms in their faeces to other contaminating sources such as water and other animals. Therefore geese could play a potential role in the transmission of Arcobacter spp. to humans and other animals since the geese are in very close contact with other animals and with family members in the region.

The findings of the present study demonstrate that various species of Arcobacter are found in domestic geese. Three Arcobacter spp., A. butzleri, A. cryaerophilus and A. skirrowii which are accepted as the sole pathogenic species for humans and animals were detected in goose cloacae in this study. The dominant species were A. cryaerophilus and A. skirrowii, with $A$. butzleri the least prevalent species in the samples analysed (see also Table 2). These three Arcobacter spp. have also been detected in other poultry species (Ridsdale et al., 1998; Atabay et al., 2006). This indicates that poultry including geese can harbour a variety of Arcobacter species in their cloacae.

Interestingly, none of the A. cryaerophilus and five of the seven A. skirrowii strains isolated in this study were able to grow at $37{ }^{\circ} \mathrm{C}$ microaerobically. None of the A. skirrowii strains of this study showed alphahaemolytic activity on blood agar. This is interesting since alpha-haemolytic activity is a distinctive characteristic of $A$. skirrowii although non-haemolytic strains of A. skirrowii are occasionally reported (On et al., 1996; Atabay et al., 2006).

In conclusion, the results of the current study suggest that domestic geese are naturally colonized with various species of Arcobacter and may play a role as reservoirs in their dissemination. The relatively high prevalence of Arcobacter spp. detected in a limited number of goose samples analysed in the present study may be of significance. More research is required to establish the true epidemiology and/or prevalence of Arcobacter spp. in geese and to determine the exact role of these poultry species for the transmission of Arcobacter spp. to humans and animals.

\section{References}

Atabay, H.I., Corry, J.E.L., 1997. The prevalence of campylobacters and arcobacters in broiler chickens. J. Appl. Microbiol. 83, 619626.

Atabay, H.I., Corry, J.E.L., 1998. Evaluation of a new arcobacter enrichment medium and comparison with two media developed for enrichment of Campylobacter spp. Int. J. Food Microbiol. 41, 53-58.

Atabay, H.I., Waino, M., Madsen, M., 2006. Detection and diversity of various Arcobacter species in Danish poultry. Int. J. Food Microbiol. 109, 139-145. 
Aydin, F., Gümüşsoy, K.S., Atabay, H.I., Iça, T., Abay, S., 2007. Prevalence and distribution of Arcobacter species in various sources in Turkey and molecular analysis of isolated strains by ERIC-PCR. J. Appl. Microbiol. 103, 27-35.

Collins, C.I., Wesley, I.V., Murano, E.A., 1996. Detection of Arcobacter spp. in ground pork by modified plating methods. J. Food Prot. 59, 448-452.

de Boer, E., Tilburg, J.J., Woodward, D.L., Lior, H., Johnson, W.M., 1996. A selective medium for the isolation of Arcobacter from meats. Lett. Appl. Microbiol. 23, 64-66.

de Oliveira, S.J., Baetz, A.L., Wesley, I.V., Harmon, K.M., 1997. Classification of Arcobacter species isolated from aborted pig fetuses and sows with reproductive problems in Brazil. Vet. Microbiol. 57, 347-354.

Dogan, M.U., Atabay, H.I., 2006. Investigation of the prevalence of Arcobacter spp. in domestic geese (Anser anser).In: Abstracts of the VIIth National Veterinary Micobiology Congress (with International Attendance), Side, Antalya, Turkey, September 26-28, 2006, p. 197.

Ellis, W.A., Neill, S.D., O’Brien, J.J., Ferguson, H.W., Hanna, J., 1977. Isolation of Spirillum/Vibrio-like organisms from bovine fetuses. Vet. Rec. 100, 451-452.

Gonzales, A., Botella, S., Montes, R.M., Moreno, Y., Ferrus, M.A., 2007. Direct detection and identification of Arcobacter species by multiplex PCR in chicken and wastewater samples from Spain. J. Food. Prot. 70, 341-347.

Gude, A., Hillman, T.J., Helps, C.R., Allen, V.M., Corry, J.E.L., 2005. Ecology of Arcobacter species in chicken rearing and processing. Lett. Appl. Microbiol. 41, 82-87.

Houf, K., Tutenel, A., De Zutter, L., Van Hoof, J., Vandamme, P., 2000. Development of a multiplex PCR assay for the simultaneous detection and identification of Arcobacter butzleri, Arcobacter cryaerophilus and Arcobacter skirrowii. FEMS Microbiol. Lett. 193, 89-94.

Houf, K., On, S.L., Coenye, T., Mast, J., Van Hoof, J., Vandamme, P., 2005. Arcobacter cibarius sp. nov., isolated from broiler carcasses. Int. J. Syst. Evol. Microbiol. 55, 713-717.

Kabeya, H., Maruyama, S., Morita, Y., Kubo, M., Yamamoto, K., Arai, S., Izumi, T., Kobayashi, Y., Katsube, Y., Mikami, T., 2003. Distribution of Arcobacter species among livestock in Japan. Vet. Microbiol. 93, 153-158.

Lastovica, A.J., Skirrow, M.B., 2000. Clinical significance of Campylobacter and related species other than Campylobacter jejuni and C. coli. In: Nachamkin, I., Blaser, M.J. (Eds.), Campylobacter. American Society for Microbiology, Washington, DC, pp. 89-120.

Logan, E.F., Neill, S.D., Mackie, D.P., 1982. Mastitis in dairy cows associated with an aerotolerant Campylobacter. Vet. Rec. 110, 229-230.
On, S.L.W., Holmes, B., Sackin, M.J., 1996. A probability matrix for the identification of campylobacters, helicobacters and allied taxa. J. Appl. Bacteriol. 81, 425-432.

On, S.L.W., Harrington, C.S., Atabay, H.I., 2003. Differentiation of Arcobacter species by numerical analysis of AFLP profiles and description of a novel Arcobacter from pig abortions and turkey faeces. J. Appl. Microbiol. 95, 1096-1105.

Prouzet-Mauleon, V., Labadi, L., Bouges, N., Menard, A., Megraud, F., 2006. Arcobacter butzleri: underestimated enteropathogen. Emerg. Infect. Dis. 12, 307-309.

Rice, E.W., Rodgers, M.R., Wesley, I.V., Johnson, C.H., Tanner, S.A., 1999. Isolation of Arcobacter butzleri from ground water. Lett. Appl. Microbiol. 28, 31-35.

Ridsdale, J.A., Atabay, H.I., Corry, J.E.L., 1998. Prevalence of campylobacters and arcobacters in ducks at the abattoir. J. Appl. Microbiol. 85, 567-573.

Suarez, D.L., Wesley, I.V., Larson, D.J., 1997. Detection of Arcobacter species in gastric samples from swine. Vet. Microbiol. 57, 325-336.

Van Driessche, E.V., Houf, K., Vangroenweghe, F., Zutter, L.D., Hoof, J.V., 2005. Prevalence, enumerationand strain variation of Arcobacter species in the faces of healthy cattle in Belgium. Vet. Microbiol. 105, 149-154.

Vandamme, P., Falsen, E., Rossau, R., Hoste, B., Segers, P., Tytgat, R., De Ley, J., 1991. Revision of Campylobacter, Helicobacter, and Wolinella taxonomy: emendation of generic descriptions and proposal of Arcobacter gen. nov. Int. J. Syst. Bacteriol. 41, 88-103.

Vandamme, P., Vancanneyt, M., Pot, B., Mels, L., Hoste, B., Dewettinck, D., Vlaes, L., Van den Borre, C., Higgins, R., Hommez, J., Kersters, K., Butzler, J.-P., Goossens, H., 1992. Polyphasic taxonomic study of the emended genus Arcobacter with Arcobacter butzleri comb. nov. and Arcobacter skirrowii sp. nov., an aerotolerant bacterium isolated from veterinary specimens. Int. J. Syst. Bacteriol. 42, 344-356.

Wesley, I.V., Baetz, A.L., 1999. Natural and experimental infections of Arcobacter in poultry. Poult. Sci. 78, 536-545.

Wirsen, C.O., Sievert, S.M., Cavanaugh, C.M., Molyneaux, S.J., Ahmad, A., Taylor, L.T., DeLong, E.F., Taylor, C.D., 2002. Characterization of an autotrophic sulfide-oxidizing-marine Arcobacter sp. that produces filamentous sulfur. Appl. Environ. Microbiol. 68, 316-325.

Woo, P.C.Y., Chong, K.T.K., Leung, K., Que, T., Yuen, K., 2001. Identification of Arcobacter cryaerophilus isolated from a traffic accident victim with bacteremia by $16 \mathrm{~S}$ ribosomal RNA gene sequencing. Diagn. Microbiol. Infect. Dis. 40, 125-127.

Wybo, I., Breynaert, J., Lauwers, S., Lindenburg, F., Houf, K., 2004. Isolation of Arcobacter skirrowii from a patient with chronic diarrhea. J. Clin. Microbiol. 42, 1851-1852. 